\title{
Automatic generation control with nonlinear design of interconnected power system using optimization techniques
}

\author{
KunteRukmanRao ${ }^{1}$, Raja Reddy Duvvuru², Rajesh Reddy Duvvuru ${ }^{3}$ \\ PG scholar, Dept. Of EEE, JNTUA college of Engineering, Pulivendula, Kadapa(dt) A.P, India ${ }^{1}$ \\ Lecturer, Dept. Of EEE, JNTUA college of Engineering, Pulivendula, Kadapa(dt) A.P, India ${ }^{2}$ \\ Assistant Professor, Dept. Of EEE, NARAYANA college of Engineering, Guduru, Nellore(dt) A.P, India ${ }^{3}$
}

\begin{abstract}
An electric power system comprises of generation, transmission and distribution of electric energy. To meet today's load demand different generations are interconnected via tie lines. This paper deals with AGC problem of a two area thermal system using Proportional-integral-derivative controller (PID). The controller parameters are tuned by using particle swarm optimization (PSO) and Many optimizing Liaisons (MOL) algorithms. Dynamic response of the PID controlled AGC tuned by both the algorithms are compared by applying 1\% step load perturbation (SLP) in both areas at different conditions. The cost function is derived by taking the area control errors (ACE) of both the areas. The system is checked for robustness by varying the parameters of the governor, turbine and reheat from $-50 \%$ to $+50 \%$ in steps of $25 \%$. Based on analysis, facts \& figures the system is found to be robust and performs better when tuned by the MOL algorithm.
\end{abstract}

Keywords: Automatic Generation Control, Area control error, PSO and MOL algorithms, Matlab software.

\section{INTRODUCTION}

Now-a-days, modern power systems are divided into number of areas. For example, in our country, eastern grid, western grid both are connected as single grid for reliable, control, and secured operation and each area are interconnected among themselves through transmission lines, called tie-line.

Interconnected power system or power grid provides following advantages over the control area operated individually,

[1] It stabilizes the grid which in turn increases stability, reliability \& security of the overall system.

[2] Maintaining frequency to a fixed tolerance value which reduces voltage collapse $\&$ chances of undesirable load-shed situation.

Earlier days, one generating unit in a system would be designed as the regulated unit $\&$ it was manually adjusted to Control the balance between the net generation \& load demand. But now with automatic Generation system, many units are participated in regulation, improving overall system efficiency \& economy. The main function of power system operation and control is to provide continuous power supply to all consumers connected to it. Automatic Generation control (AGC) regulates real power flow between different control areas while keeping frequency constant.

The first attempt in the area of AGC has been to control the frequency of a power system via the governor of the synchronous machine. This technique was subsequently found to be insufficient and a supplementary control was included to the governor with the help of a signal directly proportional to the frequency deviation plus it's integral. This scheme constitutes the classical approach to the AGC of power systems [1]. Cohn has done very early works in this important area of AGC. Cohn [2] have presented basic important works on tie line power and frequency control and tie line bias control in interconnected systems.

Mishra and Swapna Kumar jena [3] had discussed the simulation model of hybrid system i.e., hydro thermal system. They developed a gain tuning of controller via Differential evolutionary Algorithm and dynamics performance of hybrid AGC with different controller strategies.

K. C. Divya et al [4] have discussed the simulation model of hydro-hydro systems. They showed that the difficulty in extending the traditional approach for such systems was overcome by assuming that all areas in a system operate at the same frequency. They obtained the model by ignoring the frequency difference between the control areas.

B.K Sahu and P.K. Mohanty [5] have discussed the modeling and comparative analysis of PID controller of Automatic Voltage Control system via Many Optimizing Liaisons.

The main features of AGC loops are

[1] Keeping frequency to its steady state value.

[2] To control power flow between interconnected control areas.

[3] Maintain equal load distribution among the participating units.

In this paper, PID controllers are used to improve the dynamic performance of AGC of a two area thermal system. The main aim of this work is the application of PSO and MOL algorithms to tune the parameters of the PID controllers in an interconnected system. In view of the above, the present work investigates the following aspects: i). To optimize the parameters of the conventional PID controllers using PSO and MOL algorithms. 
ii) To compare the performance PSO and MOL optimized PID controlled AGC for two area interconnected thermal power system.

\section{PROPOSED METHOD}

In order to represent a basic simple model of an interconnected power system, in this work deal with two thermal areas of equal size of $1000 \mathrm{MW}$ consisting both reheat with governor dead band mechanism. The introduction of dead band makes the system to nonlinear.

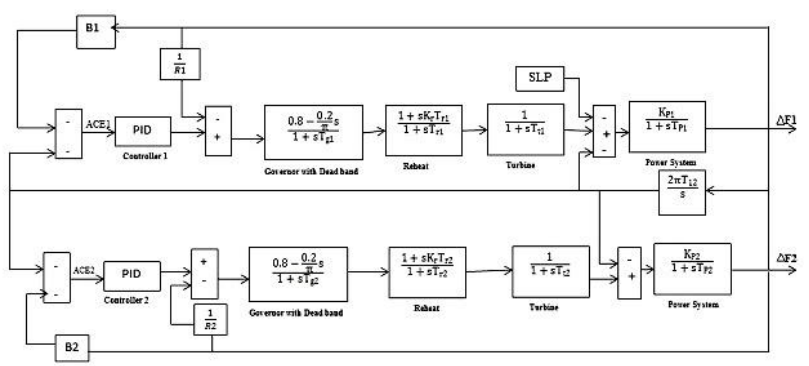

In the design of PID controllers (two in number) for this work the six gains are selected in such a way that the desired response obtained of the closed loop system which refers that the system should have a minimum settling time and a very less value of overshoot as well as undershoots with less oscillations due to a $10 \%$ Step Load Perturbation as

$\mathrm{U}_{1}=\mathrm{ACE}_{1}\left(\mathrm{~K}_{\mathrm{P} 1}+\frac{\mathrm{K}_{\mathrm{I} 1}}{\mathrm{~s}}+\right) \mathrm{K}_{\mathrm{D} 1} \mathrm{~S}$

$\mathrm{U}_{2}=\mathrm{ACE}_{2}\left(\mathrm{~K}_{\mathrm{P} 2}+\frac{\mathrm{K}_{\mathrm{I} 2}}{\mathrm{~s}}+\right) \mathrm{K}_{\mathrm{D} 2} \mathrm{~s}$

The value of Area Control Error is sum of bias factor and tie-line power deviation. The area control error in both areas consists of tie-line power error of the intermediate area and frequency error, given by

$A C E_{1}=B_{1}+\Delta P_{T I E}$

$A C E_{2}=B_{2}+\Delta P_{T I E}$

In this work, the constraint of setting the gains of PID controller is a major problem. Therefore, the PID gains should be in limits, i.e.,

$$
\begin{aligned}
\mathrm{Kp}_{\text {min }} & \leq \mathrm{K}_{\mathrm{p}_{\mathrm{i}}} \leq \mathrm{Kp}_{\text {max }} \\
\mathrm{Ki}_{\text {min }} & \leq \mathrm{K}_{\mathrm{i}_{\mathrm{i}}} \leq \mathrm{Ki}_{\text {max }} \\
\mathrm{Kd}_{\text {min }} & \leq \mathrm{K}_{\mathrm{d}_{\mathrm{i}}} \leq \mathrm{Kd}_{\text {max }}
\end{aligned}
$$

Where $\mathrm{I}$ is the number of controller gains (here $\mathrm{I}=2$ due to two controllers).

$K p_{\min }, K i_{\min }$ and $K d_{\min }$ are the minimum values of controller parameters and maximum allowable values of controller parameters are $K p_{\max }, K i_{\max }$ and $K d_{\max }$ Hence forth, in this work PID parameters are constrained within $[0,3]$.

The main aim of tuning the system is minimizing the value of Area Control Error (ACE). In order to achieve this, the cost function $\mathbf{J}$ is taken as

$J=\int_{0}^{t}\left[A C E_{i}^{2}\right] \cdot t d t$

Where $\mathrm{ACE}_{\mathrm{i}}=$ Area control error of $\mathrm{i}^{\text {th }}$ area

$\mathrm{T}=$ simulation time

\section{Tuning algorithms used in the proposed work} III.I Particle Swarm Optimization Algorithm

Particle Swarm Optimization (PSO), one of the latest meta-heuristic algorithms, was first introduced by Kennedy and Eberhartin 1995 for solving nonlinear and non-continuous optimization problems [6,7]. This algorithm uses particles which represent potential solutions of the problem. The basic principle of PSO is that it initializes a population of particles with randomness of both positions and velocities.

Subsequently, each particle adjusts its velocity dynamically corresponding to its flying experiences and its colleagues. The best previous position of the particle is recorded and represented as $\mathrm{P}$ best. The index of the best particle among all the particles in the group is represented by the $\mathrm{G}_{\text {best. }}$. The updated velocity and position of each particle can be calculated as per following formulas

$\mathrm{V}_{\mathrm{i}}^{(\mathrm{t}+1)}=\mathrm{w} \cdot \mathrm{V}_{\mathrm{i}}^{\mathrm{t}}+\mathrm{C} 1$. rand1. $\left(\mathrm{P}_{\text {best }_{\mathrm{i}}}-\mathrm{P}_{\mathrm{i}}^{\mathrm{t}}\right)+\mathrm{c} 2 \cdot \operatorname{rand} 2 \cdot\left(\mathrm{G}_{\text {best }_{\mathrm{i}}}-\mathrm{P}_{\mathrm{i}}^{\mathrm{t}}\right.$

$P_{i}^{(t+1)}=P_{i}^{t}+V_{i}^{(t+1)}$

Here $\mathrm{w}$ is the inertia weight parameter which controls the global and local exploration capabilities of the particle. ' $\mathrm{C} 1$ ' and ' $\mathrm{C} 2$ ' are acceleration constants and, 'rand1' and 'rand2' are random numbers between 0 and 1 . In this study the values of $\mathrm{C} 1$ and $\mathrm{C} 2$ are taken as 2.05. At the end of the iterations, the best position of the swarm will be the solution of the problem. The basic steps of PSO algorithm is represented below:

\section{Steps for PSO algorithm}

a) Randomly, initialize the positions and velocities of each particle

b) Update the position and velocity of each particle.

c) Update the personal and global best.

d) Find the velocity of a new particle using (6).

e) Using (7) move the particle to a new position.

f) Enforce search space boundaries.

g) Update the particle's best position, if $\mathrm{f}(\mathrm{Vi})<\mathrm{f}(\mathrm{P}$

best)

h) The above steps are repeated for swarm's best position $\mathrm{f}\left(\mathrm{G}_{\text {best }}\right)$

\section{III.II MOL ALGORITHM}

In many optimizing liaisons (MOL) algorithm it is possible to simplify the PSO method somewhat by removing the use of an agent's own best known position from the velocity recurrence relation. This PSO variant is known here sometimes as the "social only" PSO [5]. The MOL method is studied most extensively in (3)(5).

Velocity Update

By setting the swarm's best position to zero in PSO algorithm, makes particle not to have any persistence in the previously followed path, this gives velocity update for the MOL method is as follows:

$\mathrm{V}_{\mathrm{i}}^{(\mathrm{t}+1)}=\mathrm{w} \cdot \mathrm{V}_{\mathrm{i}}^{\mathrm{t}}+\mathrm{c} \cdot \operatorname{rand}\left(\mathrm{G}_{\text {best }_{\mathrm{i}}}-\mathrm{P}_{\mathrm{i}}^{\mathrm{t}}\right)$

$P_{i}^{(t+1)}=P_{i}^{t}+V_{i}^{(t+1)}$ 
INTERNATIONAL JOURNAL OF INNOVATIVE RESEARCH IN ELECTRICAL, ELECTRONICS, INSTRUMENTATION AND CONTROL ENGINEERING Vol. 2, Issue 12, December 2014

\section{RESULTS AND DISCUSSION}

In order to optimize the gains of the PID controllers 100 iterations are considered for both PSO and DE algorithm. The upper and the lower limits for the controller's gains are respectively taken as 0.1 and 2.5. A small step load perturbation (SLP) of $1 \%$ is applied to both areas for studying the transient response of the PID controlled AGC. The optimum values of PID controller gains are depicted in table I.

TABLE I Optimum gains of PID controller of both areas tuned by PSO and MOL algorithms

\begin{tabular}{|c|c|c|c|c|c|c|}
\hline Algorithm & \multicolumn{3}{|c|}{$\begin{array}{c}\text { PID controller gains for } \\
\text { area-1 }\end{array}$} & \multicolumn{3}{c|}{$\begin{array}{c}\text { PID controller gains for } \\
\text { area-2 }\end{array}$} \\
\hline Parameters & Kp1 & Ki1 & Kd1 & Kp2 & Ki2 & Kd2 \\
\hline PSO & 2.3030 & 2.3399 & 1.9963 & 1.7643 & 1.4254 & 1.3597 \\
\hline MOL & 1.1112 & 1.8311 & 1.4328 & 1.4251 & 2.2472 & 2.2194 \\
\hline
\end{tabular}

TABLE II Settling time and peak overshoots of $\Delta \mathrm{F} 1, \Delta \mathrm{F} 2$ and $\Delta$ Ptie

\begin{tabular}{|c|c|c|c|l|l|c|}
\hline \multirow{2}{*}{ Algorithm } & \multicolumn{5}{|c|}{ Dynamic response } \\
\cline { 2 - 7 } & \multicolumn{2}{|c|}{$\Delta$ F1 } & \multicolumn{2}{c|}{$\Delta$ F2 } & \multicolumn{2}{c|}{$\Delta$ Ptie } \\
\cline { 2 - 7 } & $\begin{array}{c}\text { Ts in } \\
\text { sec }\end{array}$ & $\begin{array}{c}\text { Osh in } \\
\text { p.u }\end{array}$ & $\begin{array}{c}\text { Ts in } \\
\text { sec }\end{array}$ & $\begin{array}{c}\text { Osh in } \\
\text { p.u }\end{array}$ & $\begin{array}{l}\text { Ts in } \\
\text { sec }\end{array}$ & $\begin{array}{c}\text { Osh in } \\
\text { p.u }\end{array}$ \\
\hline \multirow{2}{*}{ PSO } & 28.99 & - & 22.35 & - & 23.46 & -0.999 \\
& & 0.9816 & & 0.9836 & & -0.999 \\
\hline \multirow{2}{*}{ MOL } & 21.87 & - & 23.42 & - & 21.29 & -0.9836
\end{tabular}

From fig.2, fig.3 andfig.4 respectively shows the variations in $\triangle F 1, \Delta F 2$ and $\triangle$ Ptiefor both PSO and MOL algorithms and thus conculds that MOL has better transient behaviour over PSO algorithm.

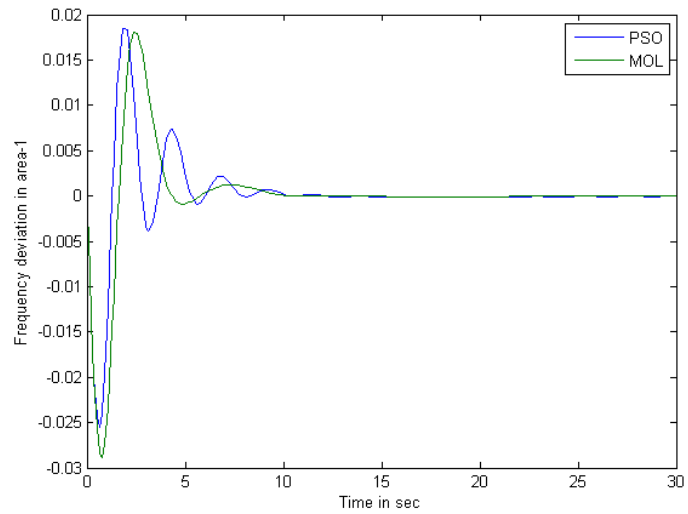

Figure 2 Frequency deviation in area-1

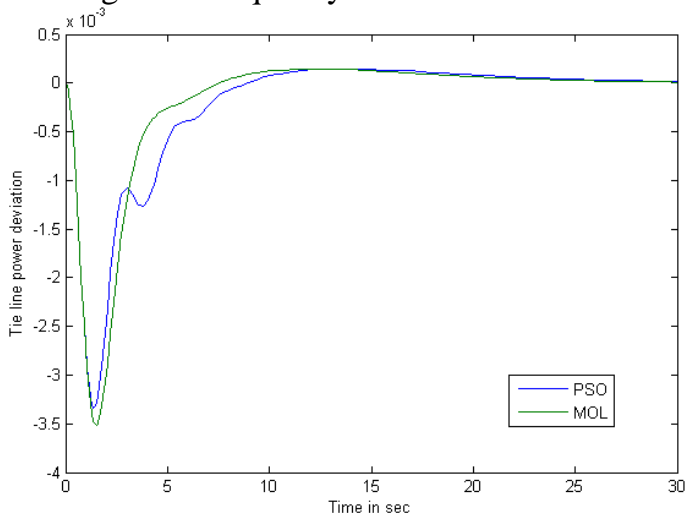

Figure 3 Frequency deviation in area-I

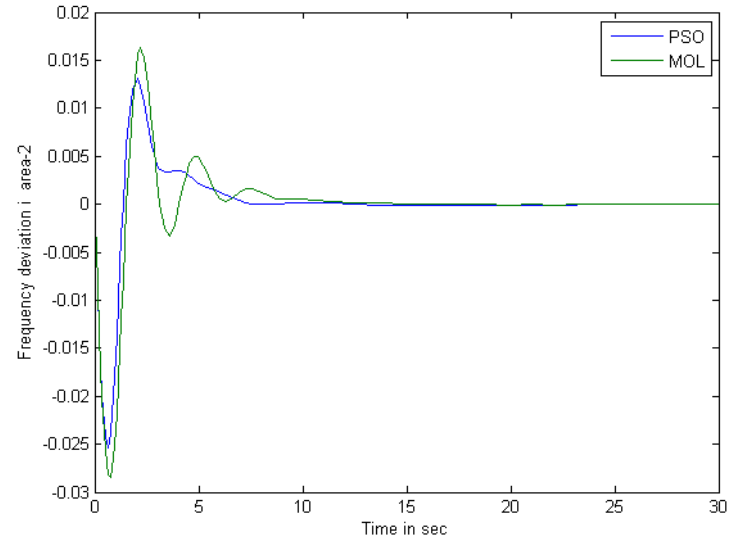

Figure 4 Tie Line power deviation

\section{V.ROBUSTNESS ANALYSIS}

Each thermal areas consists of non-linear governor with time constant, turbine with time constant and reheat with gain as \& time constant. For robustness analysis all these parameters are varied from $-50 \%$ to $+50 \%$ in steps of $25 \%$ by applying 1\% SLP in both areas. The controller gains obtained from PSO and MOL algorithm are used to study the robustness of the system.

Table III and Table IV shows the trasient response behaviour of interconnected system optimization using PSO algorithm.

TABLE III Settling time values for $\Delta \mathrm{F} 1, \Delta \mathrm{F} 2$ and $\Delta \mathrm{Ptie}$

\begin{tabular}{|c|c|c|c|c|}
\hline Parameters & $\begin{array}{c}\% \text { age } \\
\text { deviation }\end{array}$ & $\begin{array}{c}\text { Ts for } \\
\Delta F 1 \text { (in } \\
\text { sec) }\end{array}$ & $\begin{array}{c}\text { Ts for } \\
\Delta F 2 \text { (in } \\
\text { sec) }\end{array}$ & $\begin{array}{l}\text { Ts for } \\
\Delta \text { Ptie (in } \\
\text { sec) }\end{array}$ \\
\hline \multirow[t]{5}{*}{$\mathbf{T g}$} & $50 \%$ & 22.01 & 23.65 & 21.67 \\
\hline & $25 \%$ & 22.28 & 23.51 & 21.87 \\
\hline & Normal & 21.87 & 23.42 & 21.99 \\
\hline & $-25 \%$ & 22.28 & 23.51 & 21.87 \\
\hline & $-50 \%$ & 22.01 & 23.65 & 21.67 \\
\hline \multirow[t]{5}{*}{$\mathbf{T t}$} & $50 \%$ & 22.29 & 24.35 & 22.02 \\
\hline & $25 \%$ & 22.42 & 27.85 & 22.25 \\
\hline & Normal & 21.87 & 23.42 & 21.99 \\
\hline & $-25 \%$ & 22.19 & 24.68 & 2219 \\
\hline & $-50 \%$ & 22.37 & 23.68 & 21.97 \\
\hline \multirow[t]{5}{*}{$\mathbf{K r}$} & $50 \%$ & 30 & 30 & 24.37 \\
\hline & $25 \%$ & 23.67 & 24.61 & 20.40 \\
\hline & Normal & 21.87 & 23.42 & 21.99 \\
\hline & $-25 \%$ & 30 & 30 & 30 \\
\hline & $-50 \%$ & $29 / .98$ & 29.99 & 28.37 \\
\hline \multirow[t]{5}{*}{ Tr } & $50 \%$ & 19.53 & 22.33 & 15.11 \\
\hline & $25 \%$ & 14.17 & 14.43 & 14.57 \\
\hline & Normal & 21.87 & 23.42 & 21.99 \\
\hline & $-25 \%$ & 12.24 & 1440 & 8.54 \\
\hline & $50 \%$ & 16.28 & 16.84 & 13.44 \\
\hline
\end{tabular}


INTERNATIONAL JOURNAL OF INNOVATIVE RESEARCH IN ELECTRICAL, ELECTRONICS, INSTRUMENTATION AND CONTROL ENGINEERING Vol. 2, Issue 12, December 2014

TABLE IV \%Over Shoot for $\Delta \mathrm{F} 1, \Delta \mathrm{F} 2$ and $\Delta \mathrm{Ptie}$

\begin{tabular}{|c|c|c|c|c|}
\hline Parameters & $\begin{array}{c}\% \text { age } \\
\text { deviation }\end{array}$ & $\begin{array}{c}\text { \%Osh } \\
\text { for } \\
\Delta \mathrm{F} 1 \text { (in } \\
\text { sec) }\end{array}$ & $\begin{array}{c}\% \text { Os } \\
\text { for } \\
\Delta \mathrm{F} 2 \text { (in } \\
\text { sec) }\end{array}$ & $\begin{array}{c}\% \text { Os for } \\
\Delta \text { Ptie (in } \\
\quad \text { sec) }\end{array}$ \\
\hline \multirow[t]{5}{*}{$\mathrm{Tg}$} & $50 \%$ & -0.9918 & -0.9924 & -0.9909 \\
\hline & $25 \%$ & -0.9928 & -0.9939 & -0.9907 \\
\hline & Normal & -0.9816 & -0.9836 & -0.999 \\
\hline & $-25 \%$ & -0.9808 & -0.9777 & -0.9973 \\
\hline & $-50 \%$ & -0.9782 & -0.9782 & -0.9972 \\
\hline \multirow[t]{5}{*}{$\mathbf{T t}$} & $50 \%$ & -0.9949 & -0.9965 & -0.99 \\
\hline & $25 \%$ & -0.9950 & -0.9966 & -0.9902 \\
\hline & Normal & -0.9816 & -0.9836 & -0.999 \\
\hline & $-50 \%$ & -0.9795 & -0.9768 & -0.9977 \\
\hline & $-25 \%$ & -0.9839 & -0.9809 & -0.9979 \\
\hline \multirow[t]{5}{*}{$\mathbf{K r}$} & $50 \%$ & -0.9877 & -0.9899 & -0.9997 \\
\hline & $25 \%$ & -0.9714 & -0.9763 & -0.9990 \\
\hline & Normal & -0.9816 & -0.9836 & -0.999 \\
\hline & $-25 \%$ & -0.9113 & -0.9822 & -0.9922 \\
\hline & $-50 \%$ & -0.9680 & -0.9640 & -0.9945 \\
\hline \multirow[t]{5}{*}{$\mathbf{T r}$} & $50 \%$ & -0.9882 & -0.9893 & -0.9923 \\
\hline & $25 \%$ & -0.9902 & -0.9903 & -1.0 \\
\hline & Normal & -0.9816 & -0.9836 & -0.9999 \\
\hline & $-25 \%$ & -0.9749 & -0.9720 & -0.9969 \\
\hline & $-50 \%$ & -0.9746 & -0.9719 & -0.9967 \\
\hline
\end{tabular}

Table $\mathrm{V}$ and Table VI respectively shows the transient behaviour of interconnected power system optimization using MOL algorithm.

From the tables the robustness analysis gives the idea of controlled operation of particular respective tuned PID gain values with a $1 \%$ step disturbance on both areas and we can restore the system into a new operating point with minimum deviation in ACE.

TABLE V Settling time values for $\Delta \mathrm{F} 1, \Delta \mathrm{F} 2$ and $\Delta \mathrm{Ptie}$

\begin{tabular}{|c|c|c|c|c|}
\hline Parameters & $\begin{array}{c}\text { \% age } \\
\text { deviation }\end{array}$ & $\begin{array}{c}\text { Ts for } \\
\Delta \text { F1 (in } \\
\text { sec) }\end{array}$ & $\begin{array}{c}\text { Ts for } \\
\mathbf{\Delta F 2} \text { (in } \\
\text { sec) }\end{array}$ & $\begin{array}{c}\text { Ts for } \\
\Delta \text { Ptie (in } \\
\text { sec) }\end{array}$ \\
\hline \multirow{4}{*}{ Tg } & $50 \%$ & 25.82 & 21.47 & 23.49 \\
\cline { 2 - 5 } & $25 \%$ & 25.88 & 20.66 & 23.65 \\
\cline { 2 - 5 } & Normal & 28.99 & 22.35 & 23.46 \\
\cline { 2 - 5 } & $-25 \%$ & 26.28 & 14.55 & 23.66 \\
\cline { 2 - 5 } & $-50 \%$ & 25.92 & 21.18 & 23.18 \\
\hline Tt & $50 \%$ & 26.72 & 15.12 & 24.02 \\
\cline { 2 - 5 } & $25 \%$ & 29.24 & 15.40 & 24.24 \\
\cline { 2 - 5 } & Normal & 28.99 & 22.35 & 23.46 \\
\cline { 2 - 5 } & $-25 \%$ & 26.75 & 15.25 & 23.99 \\
\cline { 2 - 5 } & $-50 \%$ & 27.63 & 14.99 & 23.55 \\
\hline \multirow{6}{*}{ Kr } & $50 \%$ & 25.98 & 26.40 & 22.82 \\
\cline { 2 - 5 } & $25 \%$ & 27.35 & 28.58 & 20.66 \\
\cline { 2 - 5 } & Normal & 28.99 & 22.35 & 23.46 \\
\cline { 2 - 5 } & $-25 \%$ & 29.62 & 29.64 & 22.96 \\
\cline { 2 - 5 } & $-50 \%$ & 30 & 30 & 30 \\
\hline Tr & $50 \%$ & 18.85 & 18.84 & 16.08 \\
\cline { 2 - 5 } & $25 \%$ & 11.42 & 12.70 & 9.58 \\
\cline { 2 - 5 } & Normal & 28.99 & 22.35 & 23.46 \\
\cline { 2 - 5 } & $-25 \%$ & 29.35 & 26.95 & 21.97 \\
\cline { 2 - 5 } & $50 \%$ & 21.93 & 24.89 & 14.89 \\
\hline
\end{tabular}

TABLE VI \% Over Shoot calculation for $\Delta \mathrm{F} 1, \Delta \mathrm{F} 2$ and $\Delta$ Ptie

\begin{tabular}{|c|c|c|c|c|}
\hline $\begin{array}{c}\text { Parameter } \\
\text { S }\end{array}$ & $\begin{array}{c}\% \text { age } \\
\text { deviation }\end{array}$ & $\begin{array}{c}\% \text { Osh for } \\
\Delta \mathrm{F} 1 \text { (in sec) }\end{array}$ & $\begin{array}{c}\% \text { Os for } \\
\Delta \mathrm{F} 2 \text { (in } \\
\text { sec) }\end{array}$ & $\begin{array}{c}\% \text { Os for } \\
\Delta \text { Ptie (in } \\
\text { sec) }\end{array}$ \\
\hline \multirow[t]{5}{*}{$\mathrm{Tg}$} & $50 \%$ & -0.9884 & -0.9918 & -0.999 \\
\hline & $25 \%$ & -0.9877 & -0.9921 & -0.9999 \\
\hline & Normal & -0.9819 & -0.9868 & -0.9993 \\
\hline & $-25 \%$ & -0.9775 & -0.9811 & -0.9979 \\
\hline & $-50 \%$ & -0.9750 & -0.9785 & -0.9969 \\
\hline \multirow[t]{5}{*}{$\mathbf{T t}$} & $50 \%$ & -0.9925 & -0.9939 & -0.9989 \\
\hline & $25 \%$ & -0.9931 & -0.9940 & -0.9979 \\
\hline & Normal & -0.9819 & -0.9868 & -0.9993 \\
\hline & $-25 \%$ & -0.9809 & -0.9832 & -0.9976 \\
\hline & $-50 \%$ & -0.9768 & -0.9797 & -0.9975 \\
\hline \multirow[t]{5}{*}{$\mathbf{K r}$} & $50 \%$ & -0.9818 & -0.9860 & -0.9995 \\
\hline & $25 \%$ & -0.9644 & -0.9688 & -0.9975 \\
\hline & Normal & -0.9819 & -0.9868 & -0.9999 \\
\hline & $-25 \%$ & -0.9217 & -0.9848 & -0.9919 \\
\hline & $-50 \%$ & -0.9637 & -0.9678 & -0.9942 \\
\hline \multirow[t]{5}{*}{$\mathbf{T r}$} & $50 \%$ & -0.9815 & -0.9868 & -0.9995 \\
\hline & $25 \%$ & -0.9837 & -0.9898 & -0.999 \\
\hline & Normal & -0.9819 & -0.9869 & -0.9999 \\
\hline & $-25 \%$ & -0.9718 & -0.9751 & -0.9968 \\
\hline & $-50 \%$ & -0.9714 & -0.9748 & -0.9966 \\
\hline
\end{tabular}

\section{CONCLUSION}

The objective of this paper is to obtain the optimum values of PID controller parameters using Many Optimization Liaisons as well as Particle Swarm Optimization algorithm for an AGC of an two area interconnected system. The performances of the proposed algorithms were compared. The results obtained from the simulation studies show that the MOL tuned system achieves better dynamic performance. From the study it can be concluded that PID controlled AGC for the two or multi area interconnected system tuned by MOL algorithm gives acceptable and reliably manage the frequency and tie line power deviations in comparatively better and faster way as compared with PSO algorithm.

\section{REFERENCES}

[1] Siva Nagaraju., "Power system operation and control" ,Pearson Publications.

[2] Cohn N. "Some aspects of tie-line bias control on interconnected power systems". Am Inst Elect Eng Trans 75 (1957) 1415-36.

[3] Prof J Nanda, Dr. M L Kothari, "Sample data AGC of HydroThermal system considering GRC”, IEEE-trans., September 21,1989.

[4] K C. Divya et al "The simulation model of hydro-hydro systems" IJTPE vol 5 December 2013.

[5] B K Sahu, P K Mohanti, "Design and comparative performance analysis of PID controlled AVC by MOL", IEEE conference. april 2012.

[6] Particle Swarm Optimization. Kennedy, J. and Eberhart,R.Perth,Australia: IEEE International Conference on Neural Networks, 1995

[7] A Modified Particle Swarm Optimizer. Shi, Y. and Eberhart, R. Anchorage, AK, USA: IEEE International Conference on Evolutionary Computation, 1998.

\section{BIOGRAPHIES}

Mr.Kunte RumanRao, was born in 1990.He received B.Tech Electrical and Electronics Engineering from JNTUA,Anantapur, in 2011 and pursuing M.Tech(Electrical power system) from JNTUA, Pulivendula, A.P. His research area includes power system operation and control, and its application. 
INTERNATIONAL JOURNAL OF INNOVATIVE RESEARCH IN ELECTRICAL, ELECTRONICS, INSTRUMENTATION AND CONTROL ENGINEERING Vol. 2, Issue 12, December 2014

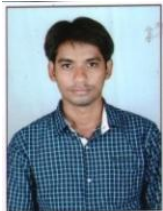

Mr. Raja Reddy Duvvuru, was born in 1988. He presently lecturer in Electrical and Electronics Department in JNTUA, Pulivendula, and he is received Master Degree in Electrical Power Engineering (EPE)from SITAMS, Chittor, in 2011 and pursing his Ph.D in JNTUA, Anantapur,A.Pin the area of Power quality improvement. His research area includes Power quality and FACTS controller.

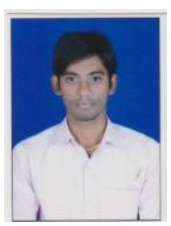

Mr. Rajesh Reddy Duvvuru,was born in 1988. He presently Assitant Professor in Electrical and Electronics Department in NEC, Guduru, and he is received Master Degree in Energy system Engineering (ESE)from JNTU, Anantapur, in 2011 His research area includes Solar energy systems and its applications. 